\title{
Knockout of alpha(1D) - adrenergic receptor affects the BDNF-ERK pathway in prefrontal cortex of mice brain: modulation by antidepressant drugs
}

\author{
I. Nalepa, K. Chorązka, J. Kuśmierczyk, J. Śmiałek, M. Kowalska \\ Maj Institute of Pharmacology, Polish Academy of Sciences, Dept. of Brain Biochemistry, Kraków, Poland
}

\section{Objectives}

To determine whether alpha(1D)-adrenergic receptor is involved in mechanism of action of antidepressant drugs and to assess its role in regulation of the brain-derived neurotrophic factor (BDNF) - the extracellular signal-regulated kinase (ERK) pathway.

\section{Background}

Neurotrophic factors are critical for the etiology and treatment of depression. The brain-derived neurotrophic factor (BDNF) production may be stimulated by noradrenaline what can be mediated by alpha(1)-adrenergic receptor ( $\alpha 1-A R)$. There are three subtypes of a1-AR family named $\alpha 1 \mathrm{~A}-$, $\alpha 1 \mathrm{~B}-$ and $\alpha 1 \mathrm{D}-\mathrm{AR}$ which are expressed in brain. Chronically given antidepressant were shown to induce changes in density of various receptors including a1-ARs. We aimed to evaluate the effect of knockout of $\alpha 1 \mathrm{D}-\mathrm{AR}$ and chronic treatment with antidepressant drugs on expression of selected proteins: BDNF and signaling proteins - the extracellular signal-regulated kinases $(E R K 1 / 2)$ and the cAMP response element-binding protein (CREB), which are downstream to the BDNF-activated TrkB receptor (Fig. 1).

\section{Materials and Methods}

The study was performed in male mice devoid of the a1D-AR (a1D-KO) and in wild type (wt) controls. The a1D-KO mouse colony was derived from triple a1ABD-KO line which was then crossed with C57BI6/J mice and bred to receive a single a1D-KO colony. Mice were chronically treated (21 days) with desipramine $(20 \mathrm{mg} / \mathrm{kg})$ or milnacipran (30 mg/kg, i.p.) or saline. The level of the signaling proteins in basal and phosphorylated forms were analyzed by Western blot in the cerebral prefrontal cortex (PFC).

Fig 3. A

\section{0
0
0}
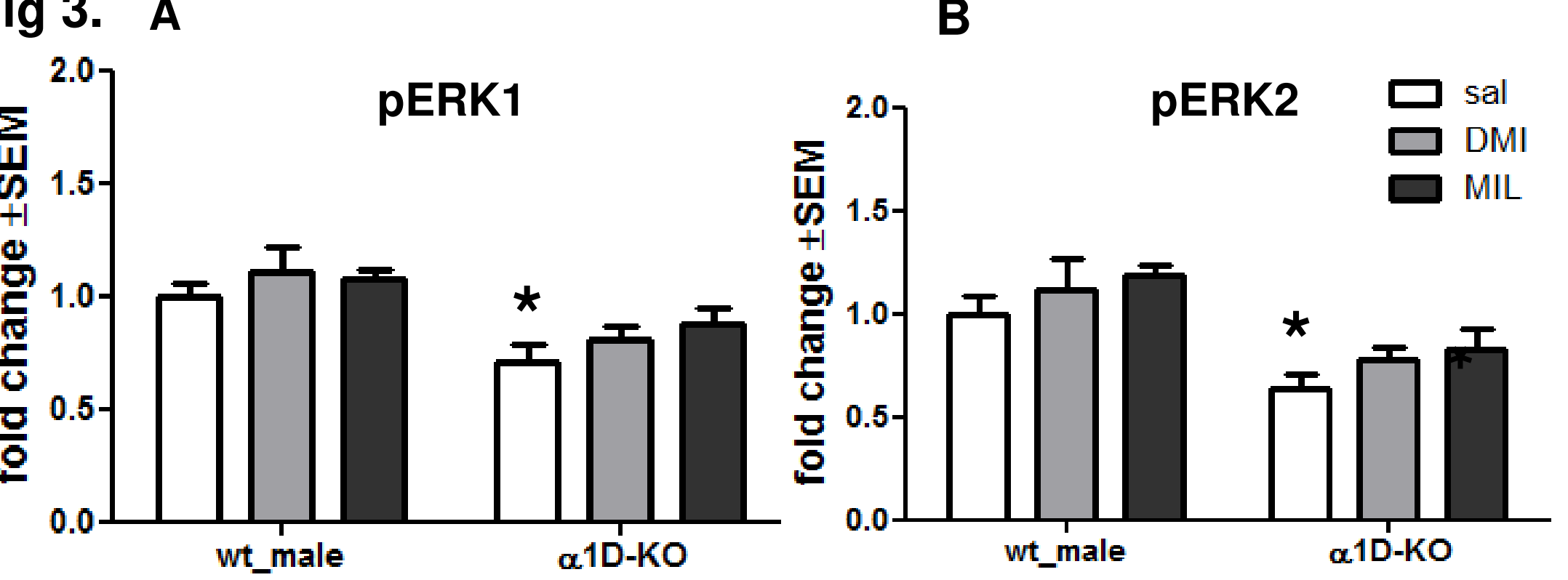

\section{Results and Conclusions}

The most important finding was that the a1D-KO mice display decreased BDNF expression level (Fig. 2) $[F(1,41=8.205, p<0.01]$ and the reduction in ERK1 and ERK2 phosphorylation (Figs. 3A and 3B) $[F(1,41=19.575$, $p<0.001]$ and $[F(1,41=25.001, p<0.001]$. The effect of drugs were seen in the case of BDNF which was slightly decreased by desipramine in wt and in the ERK2 phosphorylation level reduced by chronic milnacipran.

* We conclude that the a1D-AR participates in regulation of BDNF expression and of ERKs activation but this receptor is less important (if at all) for the effect of investigated antidepressant drugs.

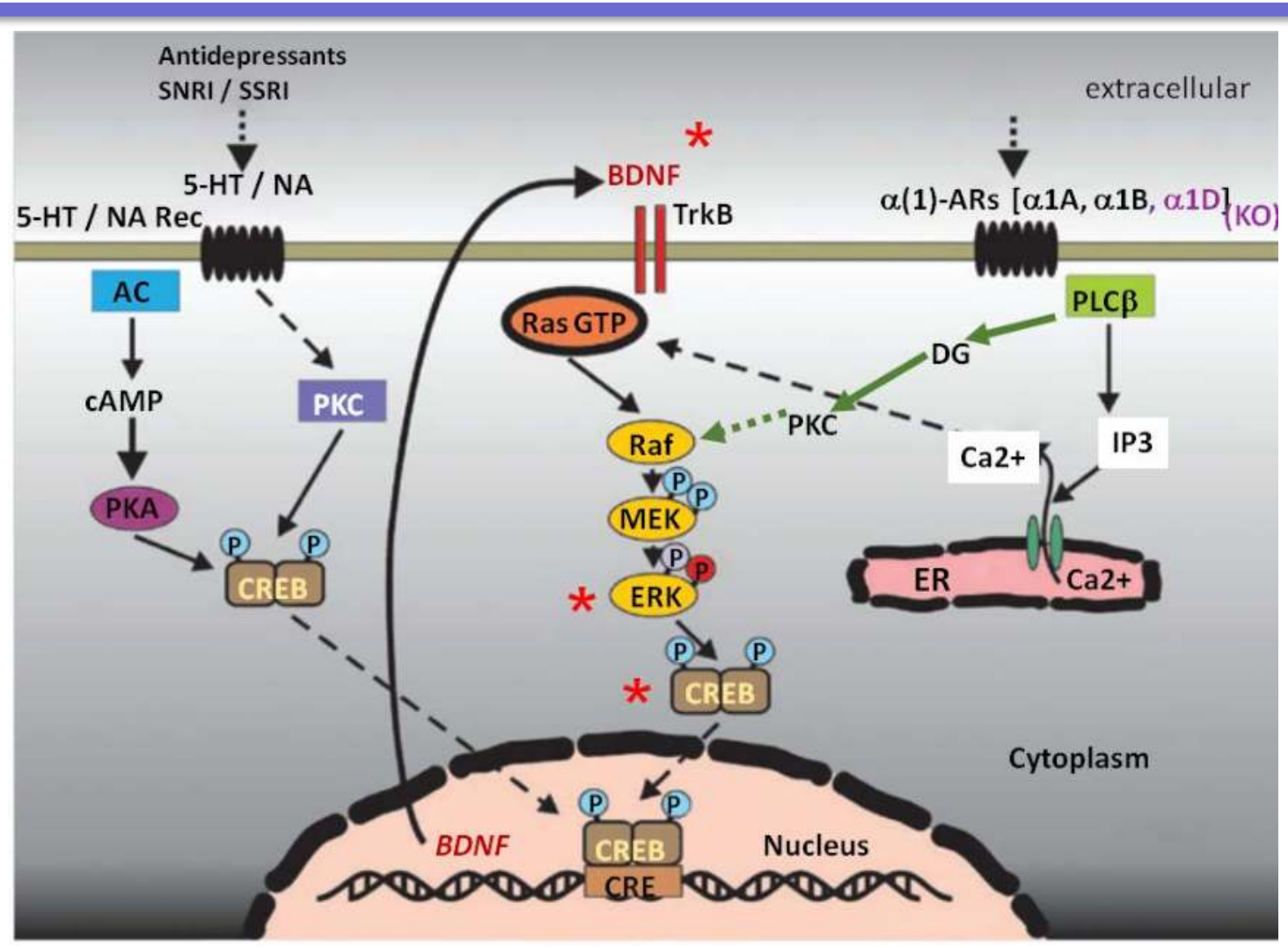

Fig 1. Signaling cascades of $\alpha 1-A R s$ and of BDNF with levels of their interaction. Antidepressant drugs act through serotoninergic and adrenergic transmission. Asterisks denote the proteins investigated in this experiment; $\mathrm{KO}$ indicates a1D knockout.

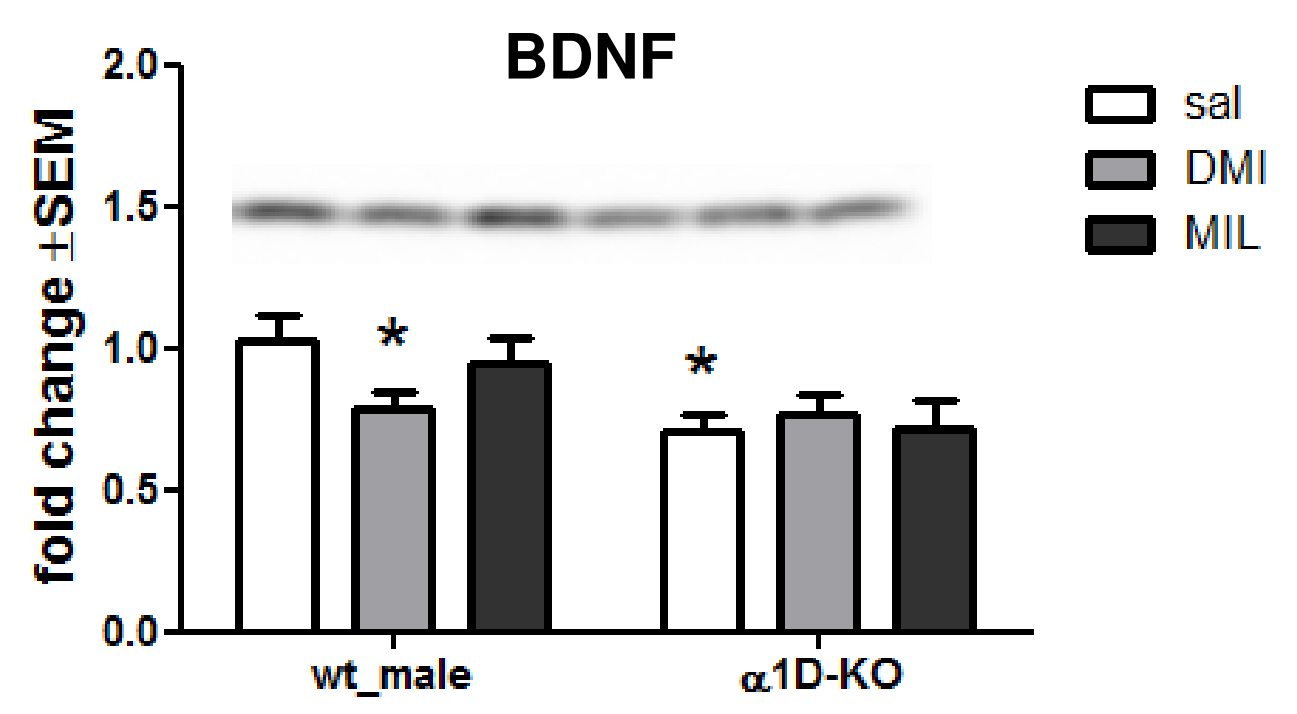

Fig 2. The expression of BDNF in PFC of wt and a1D$\mathrm{KO}$ mice. Data are expressed as mean \pm SEM relative to wt male sal group that were set as 1 . Number of animals in groups $\mathrm{N}=7-8$. ${ }^{*} \mathrm{p}<0.05$ vs wt sal.

C

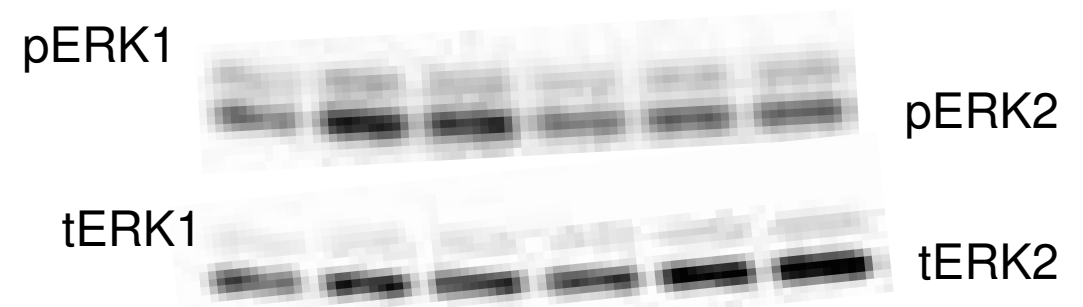

Fig 3. The phosphorylation of ERK1 (Fig $3 A$ ) and ERK2 (Fig 3B) in PFC of wt and a1D-KO mice. Data are expressed as mean \pm SEM relative to $w t$ male sal group that were set as 1 . Number of animals in groups $\mathrm{N}=7-8$. ${ }^{*} p<0.05$ vs wt sal. Fig. $3 \mathrm{C}$ : representative Western blot.

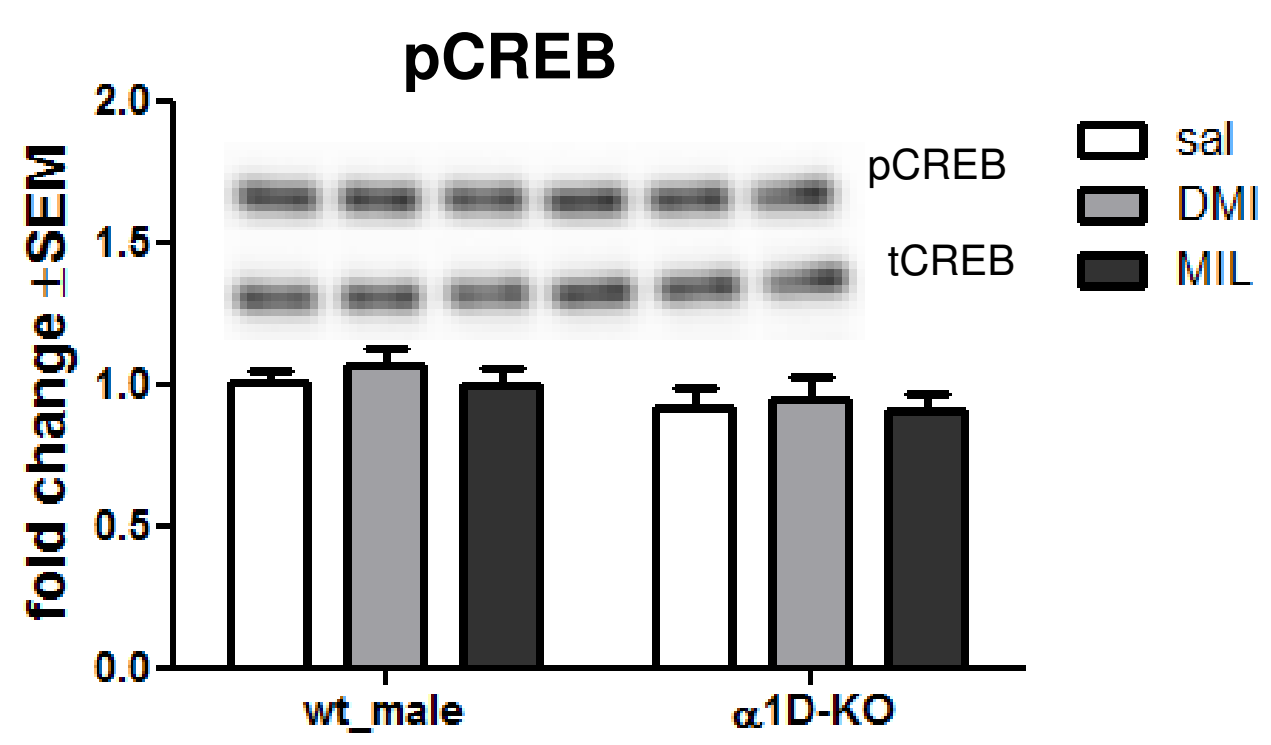

Fig 4. The phosphorylation of CREB (Fig 4) in PFC of wt and $\alpha 1 \mathrm{D}-\mathrm{KO}$ mice. Data are expressed as mean \pm SEM relative to $w t$ male sal group that were set as 1 . Number of animals in groups $\mathrm{N}=7-8$. 